\title{
Hormonal Risk Factor
}

National Cancer Institute

\section{Source}

National Cancer Institute. Hormonal Risk Factor. NCI Thesaurus. Code C19745.

Increase in the chance of developing a disease, due to hormonal factors. 